\title{
INTERNATIONAL CO-TEACHING OF MEDICAL INFORMATICS FOR TRAINING-THE-TRAINERS IN CONTENT AND DISTANCE EDUCATION
}

\author{
Kadriye O. Lewis, Ed.D \\ Assistant Professor of Pediatrics \\ Cincinnati Children's Hospital Medical Center \\ Murat Sincan, $M D$ \\ Medical Informatics Academic Expert \\ Hacettepe University Faculty of Medicine \\ Department of Medical Education and Informatics \\ Hacettepe Universitesi \\ Sihhiye, Ankara, Turkey
}

\section{KEY WORDS}

Collaborative Teaching Online, Co-teaching Online, Online Medical Informatics, Course Development, Medical Education

\begin{abstract}
In this technologically advanced age, much emphasis is put on collaboration in education at many levels. As a result, faculty co-teaching (collaborative teaching) has grown dramatically. This paper introduces how two instructors from different countries (USA and Turkey), one experienced in online teaching and the other in medical informatics, collaborated successfully, to develop and teach an online medical informatics course. This study outlines effective strategies in co-teaching and student satisfaction with the course and includes various instructional techniques for cost effective technology for communicating at a distance.
\end{abstract}

\section{INTRODUCTION}

In education, collaboration has been desirable and valued as an important strategic concept. Most contemporary learning theories argue that the concept of collaboration is one of the cornerstones of social constructivist learning [1]. The social constructivist approach refers to the activities that promote learning through social interaction. In this respect, emphasis is put on collaboration among faculty to work together in a joint intellectual effort or practical endeavor. In a traditional sense, this collaboration would occur within the same institution, department, or discipline. However, new technologies have provided an exciting infrastructure for course delivery allowing accessibility to instruction unbound by time or space. This has created a different educational environment for today's educators to explore new frontiers to interact, collaborate, support, and empower teaching and learning.

As technologies continue to mature and change over time, we will continually explore new concepts, technology tools, and teaching methods. Exploration helps us to understand the strengths and weaknesses of various teaching methods and technology tools; how to use these tools successfully to achieve specific goals; and how to create teaching and learning relationships directly with other educators. Before 
technology-powered education, collaborative relationships were difficult to develop due to many factors such as space, time conflicts, power, influence, and professional identity and integrity. However, most educators agree that collaboration is a worthy goal in teaching and learning [2], and because of the complexities of the information age, collaboration has become an essential component of education in the United States [3].

The scope of collaboration can be quite broad within multiple dimensions, including collaboration among instructors, collaboration between students and faculty, simulation environments, electronic books, digital libraries, and virtual universities. As the Internet provides fast connectivity among faculty and students, collaboration online can be easier than in the traditional classroom setting due to real-time issues of space, schedule conflicts, noise, and resources. Instructors residing in different geographic areas can use this modern technology and design a course and co-teach by sharing a course platform such as Blackboard. The two authors of this paper have accomplished a successful instructional collaboration through coteaching (collaborative teaching), which included on-the-job training of one of the instructors (MS) who had limited experience in online teaching and online pedagogy. Both medical informatics course instructors, each providing their own particular strengths and experiences, provided effective educational experiences to their learners, despite coming from different educational disciplines and working in different countries (U.S. and Turkey). This paper describes our experience developing and co-teaching an online medical informatics course for an Online Master's Degree in Education for Healthcare Professionals program.

\section{BACKGROUND INFORMATION}

The Online Master's Degree in Education for Healthcare Professionals program was developed as a collaborative project of the University of Cincinnati College of Education (UCCOE) and the UC College of Medicine Department of Pediatrics based in the Cincinnati Children's Hospital Medical Center (CCHMC). The program (http://www.cincinnatichildrens.org/masters) was launched nationally in the fall of 2002 after piloting the program in 1999 and 2001 [4]. The target audience for the master's program is physicians, nurses, and other health professionals with significant teaching responsibilities and interests in medical education and educational research as well as clinical fellows seeking an advanced degree alternative to the more traditional M.P.H. and M.S. degrees. Twelve core courses, 3 credit hours each, plus an elective or independent study, practicum, and master's project, also 3 credit hours each, comprise the 45 credit hour program, The program curriculum is grounded in a pluralistic philosophy that encompasses the many needs of today's medical educator - the science and literature of education, technology skills, and effective application of educational pedagogy and technology-for a diverse population of healthcare professionals. Since the program's inception, 114 students have enrolled in the program, 58 females and 56 males. The mean age of participants is 40 (range 27-64). These students come from different medical and surgical specialties and sub-specialties and from 26 States and three countries (USA, Canada, and Ecuador). Except for one, the core teaching faculty come from UC College of Education and CCHMC. All faculty members have educational credentials such as Ph.D/Ed.D or MD.

\section{A. Medical Informatics}

Medical informatics is as diverse and complex a domain as medicine itself. Due to advances in computing and communications technology, medical informatics has become an emerging scientific discipline that addresses the application of computers and information technology to healthcare as well as medical education and biomedical research [5]. Medical informatics allows physicians and other health professionals to integrate advanced information system capabilities with highly trained individuals in clinical medicine. However, because of the developing nature of the field, the distribution of experts around the world is limited and not well balanced geographically, which also tends to limit education in 
International Co-Teaching of Medical Informatics for Training-the-Trainers in Content and Distance Education

the field.

In 2005, our Online Master's Degree in Education for Healthcare Professionals program began offering a three-credit-hour medical informatics elective as an alternative to the required three-credit-hour Individual Study. An Individual Study course provides the opportunity for a comprehensive, interdisciplinary educational experience, which allows students broader academic freedom to pursue a project that best suits their individual intellectual interests (or allows them to develop a deep and more complete understanding of complex subject matter under the guidance of a faculty mentor). However, individual studies may not be conducive for some students who are more successful taking a structured course. In our experience with the master's program, most physicians in the program have opted for taking an alternative course rather than developing an independent study project.

The decision to offer the course on medical informatics was made based on an informal needs assessment of the program participants and the availability of a talented academic expert (MS) in the Information Systems Office, Department of Medical Education at Hacettepe University in Turkey. The medical informatics course offered the opportunity to combine the efforts of an experienced online teacher (Kadriye O. Lewis, hereafter referred to as KOL) and an expert in medical informatics (Murat Sincan , hereafter referred to as MS). The co-teaching solution to the course offering thus benefited both the program as a new course offering and the instructor as a means to learn how to teach online.

\section{B. Co-Teaching}

The history of co-teaching in the US can be traced back to 1960 when it was advanced by legislated school reforms due to increased diverse student population [6]. Co-teaching has been an increasingly popular way of teaching in $\mathrm{K}-12$, including special education. Co-teaching has been used synonymously with collaborative teaching, team teaching and inclusion/special education. Co-teaching has been described in a variety of ways in the literature. Cook and Friend [7] defined co-teaching as "two or more professionals delivering substantive instruction to a diverse, or blended, group of students in a single physical space" (p.2). According to Cook, co-teaching is the "shared delivery of instruction" [8]. In special education, the co-teaching, the general education and the special education teachers work together in the same environment in a variety of instructional activities to provide optimal instruction to the greatest number of students.

Co-teaching is designed to promote communication and collaboration among professional educators to improve instruction for all learners. Cook and Friend [7] identified five co-teaching models in a face-toface classroom environment as shown in Table 1.

\begin{tabular}{|l|l|}
\hline $\begin{array}{l}\text { Co-Teaching } \\
\text { Models }\end{array}$ & Teacher Roles \\
\hline Lead and Support & $\begin{array}{l}\text { One teacher has the primary responsibility for planning and teaching, while the other teacher } \\
\text { offers assistance and support to individuals or small groups (e.g., observe particular behaviors } \\
\text { or distribute teaching materials). }\end{array}$ \\
\hline Station Teaching & $\begin{array}{l}\text { Students are divided into heterogeneous groups and work at classroom stations with each } \\
\text { teacher. Both teachers divide the instructional content, and each takes responsibility for } \\
\text { planning and teaching part of it. }\end{array}$ \\
\hline Parallel Teaching & $\begin{array}{l}\text { The teacher and student teacher plan jointly but split the classroom in half to teach the same } \\
\text { information at the same time. }\end{array}$ \\
\hline $\begin{array}{l}\text { Alternative } \\
\text { Teaching }\end{array}$ & $\begin{array}{l}\text { One teacher manages most of the class while the other teacher works with a small group } \\
\text { inside or outside the classroom to pre-teach, re-teach, supplement, or enrich instruction. }\end{array}$ \\
\hline
\end{tabular}


International Co-Teaching of Medical Informatics for

Training-the-Trainers in Content and Distance Education

\begin{tabular}{|l|l|}
\hline Team Teaching & $\begin{array}{l}\text { Both teachers are actively involved in the management of the lesson and discipline. Both of } \\
\text { them are responsible for planning, and they share the instruction of all students. The lessons } \\
\text { are taught by both teachers who actively engage in conversation, not lecture, to encourage } \\
\text { discussion by students }\end{array}$
\end{tabular}

Table 1: Types of Co-teaching Models in a Classroom Setting

Moreover, multi-pedagogical models for online teaching were addressed in the literature based on Lewis' study cited in Young [9] on cooperation and collaboration in team teaching. These models with six expansions are described in Table $2[9,10]$.

\begin{tabular}{|c|c|}
\hline $\begin{array}{l}\text { Co-Teaching } \\
\text { Models }\end{array}$ & Teacher Roles \\
\hline $\begin{array}{l}\text { 1. Single-teacher- } \\
\text { offering Pedagogy } \\
\text { Model }\end{array}$ & $\begin{array}{l}\text { A teacher performs several tasks (e.g., designs and develops materials, monitors work } \\
\text { progress, selects topics for discussion and responds to questions, grades papers, evaluates } \\
\text { assignments and conducts all other activities in a course.) S/he has full control of the course } \\
\text { and has to spend a lot of time to exert this control. }\end{array}$ \\
\hline $\begin{array}{l}\text { 2. Group Pedagogy } \\
\text { Model }\end{array}$ & $\begin{array}{l}\text { This model can be performed with structured interaction designed to facilitate course } \\
\text { achievement of a goal by instructors who work together in groups. A group pedagogy model } \\
\text { was divided into three models by Lin et al [10]. }\end{array}$ \\
\hline $\begin{array}{l}\text { a. Cooperative } \\
\text { pedagogy model }\end{array}$ & $\begin{array}{l}\text { Courses are run by one primary teacher with co-teachers such as teaching assistants, } \\
\text { consultants and others. }\end{array}$ \\
\hline $\begin{array}{l}\text { b. Collaborative } \\
\text { pedagogy model }\end{array}$ & $\begin{array}{l}\text { Each teaching team has a different role and team members have the same right with no } \\
\text { domination of one over the other. }\end{array}$ \\
\hline $\begin{array}{l}\text { c. Co-teaching } \\
\text { pedagogy model }\end{array}$ & Each teacher is in charge of different topics at different times. \\
\hline $\begin{array}{l}\text { 3. Cluster } \\
\text { Pedagogy Model }\end{array}$ & $\begin{array}{l}\text { Different course teachers share a single discussion board, course materials or examination } \\
\text { questions. Various teachers can integrate courses in the same domain. This model has two } \\
\text { basic divisions: }\end{array}$ \\
\hline $\begin{array}{l}\text { a. United pedagogy } \\
\text { model }\end{array}$ & $\begin{array}{l}\text { Teachers of courses in different domain may share discussion boards, examination } \\
\text { questions, announcement and experiences. }\end{array}$ \\
\hline $\begin{array}{l}\text { b. Central } \\
\text { pedagogy model }\end{array}$ & One teacher or teaching team may teach several courses with different classes. \\
\hline
\end{tabular}

Table 2: Online Pedagogy Models in Context of Co-teaching

Each of these pedagogy models may have a place in different educational environments. However, the collaborative and co-teaching models may give instructors more equal opportunities to share responsibility for instruction and student learning. If an unequal co-teaching partnership and distribution of power exists, this may lead to frustration and failure [11].

The literature in co-teaching in the healthcare area is not extensive. Orlander et al. [12] have developed a model of "co-teaching" for faculty development that can be applied to any clinical rotation. Physicians are paired to develop their teaching skills while sharing the clinical supervision of residents and medical students in the usual clinical settings (e.g., attending, teaching rounds, clinical precepting and case conferences.) As a result, co-teachers gain experience in analyzing teaching encounters and developing skills in self-evaluation. Crow and Smith [13] report the findings of a collaborative inquiry on their experience as tutors co-teaching inter-professional collaboration to a multidisciplinary group of undergraduates. They have different professional/academic backgrounds, and the student group included health and social work professionals alongside a number of non-professionals.

Both online and face-to-face co-teaching models have many components in common that lend themselves to instructional collaboration, and those models are applicable in many teaching settings. There are numerous self assessment tools available for assessing readiness to co-teach in a face-to-face class [7, 14, 
15, 16]. In addition, the challenges and benefits of co-teaching have been well documented in the literature [17].

In our masters program, a few courses used "Lead and Support" and "Parallel Teaching” models. In the Medical Informatics course we used a "Team Teaching” approach to co-teaching, which helped us blend each instructor's expertise and teaching styles to strengthen the instruction. These approaches equally distributed our responsibilities and actively involved both of us in the teaching process compared to other co-teaching models and pedagogy approaches referred in Table 1 and 2. Since the second instructor was inexperienced teaching online, this enabled the first instructor to provide on-the-job-training, which is based on the principle of learning by doing. This principle can be verified with the model developed by Orlander et al. [12] as well.

\section{Course Design and Development}

The best course design comes from a diverse, combined joint team effort by challenging and strengthening each other's ideas, as in the adage, "Two heads are better than one." One of the instructors is an expert in education and online pedagogy with an educational background in instructional design and technology. The second instructor is an expert in the content of medical informatics. Combining these strengths made the course development process faster and facilitated the "train the trainer" aspects of the course design. Thus, instructional principles and procedures were employed in a rapid mode using a flexible framework. The mixed method of various instructional design models permitted focusing on the learner's characteristics and needs.

In designing an online course, content is important, but creating experiences around the course content is also important and key to effective learning. We needed to answer a series of questions about content, scope, and interactivity of the course as a joint effort. Since the course participants' technical domain skills (e.g., technology literacy levels) were limited, the course was developed as an introductory course in medical informatics with no prerequisites other than general computer literacy (Note: students are surveyed for technology experience in the Integrating Technology Across the Curriculum course). The course content covered the following introductory topics in Medical Informatics

- Introduction to Health informatics ( The role of computers in medicine; current health system issues; the need for change; medical data)

- Standards in Health Informatics (Importance of standards in health informatics; development and maintenance of standards; different aspects of standards in health informatics; strengths and weaknesses of major standards used in health care)

- Electronic Health Record (Definition of EHR; history of the patient record; different types of health record; functional components of EHR; data entry methods for EHR)

- Clinical Information systems (Major issues in clinical information systems; clinical information systems and EHR; nursing information systems; patient monitoring systems)

- Decision support systems (Requirements for a decision support system; dimensions of clinical decision support; scientific challenges in building clinical decision support)

- Medical Imaging (Role of imaging in health care; characteristics of digital images; 2D and 3D; modalities; image analysis; integration of imaging information to medical data

- Public Health and Consumer Informatics ( Role of informatics in public health; primary care informatics; consumer access to health information)

- Bioinformatics (Sequence, structure and biological pathway information; sources for biomedical data; medical record and biomedical data; computational challenges of bioinformatics in the 
International Co-Teaching of Medical Informatics for

Training-the-Trainers in Content and Distance Education

future)

- Ethical and Moral Issues in Medical Informatics (Privacy and security in health care; Health Insurance Portability and Accountability Act (HIPAA); ethics of medical informatics practice)

After defining the course content and selecting relevant required text books, articles, and external web resources, we developed our course syllabus along with 10 detailed outlines (learning modules), one for each week. These outlines were a detailed map that contained weekly instructional topics and objectives, including reading assignments, discussion questions and grading criteria/rubrics. All other instructional materials, handouts, and PowerPoint presentations were designed and developed based on the weekly outlines instructional plan. Creating experiences around the course content was a smooth process even though writing discussion questions required dramatic rethinking of medical informatics in the practice setting. All materials were organized in folders labeled Week 1, Week 2, Week 3, etc. This organization permitted the students to navigate easily through the course materials and the instruction. Both instructors collaborated via email and Skype, a Voice over Internet Protocol (VoIP) tool, during the course design and development.

The course was conducted as a distance learning experience utilizing Blackboard and WebEx. All course materials were presented online in both asynchronous and synchronous format. Participants submitted assignments via discussion board, file exchange or digital drop box, depending on the nature of the assignment. The important instructional activities included reading, researching, discussing, completing assignments and participating in the WebEx meeting. The online week for this course was from Wednesday to Tuesday of the following week. Since all participants were full-time working professionals, this gave them more time and flexibility using their weekends for the course. Each week, discussion questions were posted on Blackboard to encourage interactive participation within the class; student participation was required and graded. Expectations for discussion board participation for each week were a direct response to the discussion questions plus a comment on another student's response. Grading of discussion board participation was based on the quality of scholarly information and dialogues using rubrics. The instructors provided weekly feedback/overview to strengthen and reinforce student knowledge. The instructors provided a "Personal Communication" area within the Discussion Board, including "Student Reflections" regarding the course materials and teaching methods.

Each student completed a final project involving research using the Internet and other academic resources based on a detailed project proposal guideline.

\section{Cost-Effective Technology Tools}

Technology costs can be serious obstacles to utilizing communication tools for online teaching. CCHMC has a site license for an Internet Enabled Conferencing Tool (WebEx) that incorporates Web conferencing, video conferencing, and teleconferencing. We use WebEx meetings to supplement the online discussions periodically, allowing students' final course presentations and masters project defense. Each meeting had some cost based on the number of students. However, other powerful technologies for synchronous communication that are available at no cost can still facilitate the teaching and learning process. For the synchronous part of the course, we communicated primarily through Skype, which can be downloaded on most computer operating systems, but does require the purchase of a microphone if one is not built into the user's system. Skype also permitted us to provide virtual office hours. Although our course platform, Blackboard, permits a visual display of material and the use of a virtual classroom with a whiteboard, Skype provides more interactive communication for synchronous meetings both for extending interrelationships of the two instructors and for students on discussion with the instructors for their group projects. We used WebEx for this course only for the participants' final project presentations 
because it permits sharing presentation documents, online searches, asking questions, interacting with other participants, printing or saving instructional materials, chatting, recording, remote control of other computers, and file transfer, all from participants' desks, some of which Skype does not offer.

\section{EFFECTIVE STRATEGIES FOR CO-TEACHING}

Keefe et al. [17] attribute successful co-teaching to: a) knowing yourself; b) knowing your partner; c) knowing your students; and d) knowing your "stuff." Following this advice to promote co-teaching in an online environment, these strategies were applied by the two instructors in the Medical Informatics course:

- We established some ground rules at the beginning of our collaboration [18]. These rules, which were negotiated between the two instructors, were needed for course development and effective instruction:

- Course development will be completed and ready to go for the spring of 2005.

- Instructor compensation will be paid at the end of the course.

- Problems with developing and teaching the course will be solved by mutual agreement.

- Mutual respect for each other's contributions and professional ethics will be preserved.

- Prompt response to emails (within 24 hours) and attendance at online meetings will be expected during the course development and teaching.

- The collaboration will be long term rather than one time teaching, and course products will be shared between instructors.

- Both parties will communicate clear expectations and consequences for behavior.

- We identified our responsibilities and common goals, and worked towards them [19]. During the course development process, the materials were exchanged back and forth for revision and editing. During the course, the first instructor (KOL) assumed responsibility for course mechanics (deploying all the materials online, posting questions weekly and sending general emails to the students), and the second instructor (MS) provided feedback to the students' postings (as content expert). He also provided the majority of supervision to the students regarding the final project.

- We displayed open, positive, honest, and frequent communication to discuss the progress of the course. Due to her experience teaching online in the master's program, the first instructor provided constant feedback regarding online teaching to the second instructor.

- We made a commitment to make the course successful building our relationship on collegiality, parity, communication, respect, and trust.

- We established consistent expectations from the learners, and both of us reflected those expectations in our teaching methods. These expectations were posted on the program course web site.

- We developed the syllabus and other instructional materials paying attention to quality, organization, and inclusion of all critical information. This was reflected in the student satisfaction and learning outcomes based on the course evaluation data.

- We encouraged a weekly journal log to be aware of the students' needs and expectations. Students who posted their reflections received extra credit, which was considered in the final grading.

- Technology support and access are necessary to online instruction. We provided timely expert technology help as needed and always had alternative technologies available in the event of technology failure (for example, WebEx as a backup to Skype).

- We were comfortable with each other's strengths and weaknesses to bring certain characteristics, 
knowledge and skills to the co-teaching situation. Because the first author of this paper is experienced in teaching both face-to-face and online environment, she was able to assist and train her co-instructor regarding online pedagogy, including course development. Her co-instructor also had high motivation to learn. Collaborative and co-teaching pedagogy models (see Table 2) were applied most of the time since these models eliminate power and domination issues for each instructor.

There were also some challenges to co-teaching across continents largely due to scheduling and educational system differences:

It was difficult to arrange the final synchronous meetings with students (WebEx) because of the seven hour time difference. This challenge was met by the second instructor volunteering to attend the synchronous meetings during non-business hours.

Cultural differences between the instructors and students led to some difficulties early in the course. The second instructor was overly cautious providing feedback to students due to concern for respect and personal sensitivity, which are rooted in culturally-based norms and practices. We were able to resolve this issue in the third week by means of a constructive discussion with the class in which these issues were acknowledged and discussed openly.

\section{STUDENT PERFORMANCE AND SATISFACTION WITH THE COURSE}

For the first offering of this elective course 13 students enrolled (Our cap is 20 students per class.); six females, seven males, age range 29 to 60 . There were multiple disciplines and a wide geographic distribution among the students (Table 3). Course retention was $100 \%$ and grades were satisfactory (eight $\mathrm{As}$, one $\mathrm{B}+$, three $\mathrm{Bs}$, and one "Incomplete" due to failure to meet the final project deadline).

\begin{tabular}{|l|l|}
\hline Discipline & States/Country \\
\hline Emergency Medicine (3) & California (1) \\
Rheumatology (1) & Ecuador (1) \\
Internal Medicine (2) & Ohio (8) \\
Education and Nursing (3) & Texas (1) \\
General Pediatrics (1) & Massachusetts (1) \\
Family Medicine (2) & Illinois (1) \\
Pediatric Pulmonary (1) & \\
\hline
\end{tabular}

Table 3: Student Demographics

We used a descriptive approach to examine course satisfaction of the students. This approach included both review of student participation and student reflections on the course.

\section{E. Student Participation}

The course was structured using weekly activities (one individual task and one group task) which resulted in very high interactivity within the class. Activities included the mandatory postings and feedback to classmates. The number of postings varied from week to week depending on the nature of the discussion questions, but there was an average of 60 postings for individual tasks each week and around 45 group postings (These postings included feedback comments, but they do not include the Student Reflections and Personal Communication postings.)

Apart from the instructors' questions, students posed questions to the instructors and classmates. The 
International Co-Teaching of Medical Informatics for Training-the-Trainers in Content and Distance Education

number of these varied from week to week, from 10 to 15 questions. The Final Projects and Personal Communication Forums were also used for asking questions to the students and instructors.

Most of the assignments were application level, and students were very engaged in the learning process as evidenced by $100 \%$ completion of the weekly assignments.

Final projects and presentations demonstrated high quality work and were completed by the due date by all but one.

The responses in \#1 and \#2 above, completed assignments (\#3), and final projects (\#4) suggested that the course objectives were met successfully as defined in the syllabus and the weekly outlines. A grading rubric was used to evaluate performance in all of these areas.

\section{F. Student Reflections}

We asked the students each week to make comments on the current week's topics and learning activities in a designated forum on the discussion board (an optional forum for extra credit). The following are some of their remarks excerpted from their reflections, which illustrate students' satisfaction with the Medical Informatics course:

"This week's reading was incredibly fascinating. Having used decision support systems, I could really relate to this topic. The information from this week's reading gives me hope in what may be available in the future in terms of improving patient safety, care and decision making."

"I liked that this course discussed a new and different topic of the medical field. It was very informative and eye opening. I learned a significant amount of information that will help broaden my scope in the design of curriculum and instruction."

"I enjoyed collaborating online with another student on my final project. ... I found the topic on electronic health records most enlightening. This was extremely helpful to me as we are currently choosing electronic health records for our health system."

"Excellent course - keep up with the hi tech!"

"Make this a mandatory part of the curriculum"

"This course has been interesting and it is amazing that this is the first time it has been taught. As someone who is no longer in the clinical environment, it is not as applicable to my daily work which is a bit disappointing. However, it has made me more aware of how information is stored and accessed which is important for me in teaching individuals who are forced to deal with such systems. It has also given me ideas for ways to store research data in a new way."

"As the class progresses I continue to see how more and more relevant this information and its application is on a daily basis. The information I am learning here will certainly be useful in the group I am joining. Currently the group is looking into integrating their EMR with the one the hospital will obtain (still up in the air). The group has been piloting VOIP, smartphones, PDAs, and tablet PCs. I look forward to using my new knowledge and online experiences in adding to their advancement." 
"Just a constructive thought. I've found it difficult at times to navigate through our required reading. I appreciate online resources and xeroxes of select chapters from texts, but I miss having complete books. The Medical Informatics Handbook is difficult to understand online, because the figures are in a different section from the tables, and in a different section from the text. I see that the handbook is available for about $\$ 65$ on Amazon and wonder whether it would be worth it for me to just go ahead and buy it. ...... The PowerPoints have been very helpful in providing an overview of the weeks material, thank you. If I had to suggest something for the next time the class is offered, I'd suggest getting the real texts. Thanks; so far the class has been very good."

\section{COURSE EVALUATION}

All students had taken at least three or more other online courses in the Online Masters program and had used the Blackboard course platform. They were also familiar with our course evaluation forms distributed at the completion of the course that focus on the presentation of the content, the pedagogical aspects of the course, teaching competency of the instructors, instructional and communication methods, and quality of the students' learning experiences. The following comments are derived from these formal course evaluations.

\section{A. PowerPoint Presentations, Handouts and Challenge Activity}

The PowerPoint presentations and other instructional materials for the course were developed based on the course goals and objectives. Since the course goals and objectives were defined in detail both in the course syllabus and the weekly outlines, students were able to match those goals and objectives with the actual course materials. In addition, weekly outlines provided a framework for students to organize their plans for successfully completing the course. These weekly outlines defined topics, objectives, major skills, knowledge, or abilities needed to perform course activities/tasks effectively, including the grading criteria. Comments from the students:

"I really like the PowerPoint presentations to help guide the reading. I too have been gratified to see the dialogue between students develop...."

"PowerPoint presentations are always helpful and effective"

"The PowerPoint summaries were most helpful to me in gaining an overview of the subject before reading the text."

"The handouts were very helpful”

Although most students indicated their positive experience with the reading materials, one student expressed feelings regarding the navigational difficulty in the online text book:

"The online textbook by van Bemmel was difficult for me as I work much easier in a linear fashion. However, I feel that including online texts like this is essential in increasing the learning curve of students or not used to using Hypertext books. So, although it is hard I think it should continue to be included."

The most positive feedback on the online instructional activities were those meant to foster student critical and creative thinking. Besides flexibility, online co-teaching supported our instructional creativity. One of the activities we developed is called "Challenge". This was expected weekly either in a group format or on an individual basis. In this activity, students or groups challenge each other with a question 
International Co-Teaching of Medical Informatics for Training-the-Trainers in Content and Distance Education

that they devised from their readings or from a search on the topic covered during the current week. Here is one example:

I hope you are well. I interacted with you last year during one of the classes. You seem to be the furthest ahead in the work this week, so how about if I pose a question so you can finish up?

My father is an adolescent medicine (pediatrics trained) physician at a college back home in Texas. Ever since I started using computers in medical school (mostly my last year) for evidence based searches and to help with patient care, he has been skeptical. He worries that somehow computers and "guidelines" will compromise the "art of medicine." Now granted, some of this may be "fear of the unknown" (It was a major feat teaching him to check email!), but, briefly, how would you begin to convince him otherwise? (Lord knows I've tried!) This week's readings touched here and there on the "art of medicine;" it made me think of this."

There were rules for the "Challenge" activity. A student or a group may only be challenged once. Students were not allowed to challenge the person/group who challenged them. If one person or group is challenged more than once (e.g. two postings at the same time by different students), the first challenge was applied and other had to be changed to a different group/student. The following comments illustrate students' feelings about this activity:

“...The challenge questions are something new... and just that-- a challenge! You really have to grasp some of the information in order to formulate a meaningful question. I'm still getting a grasp on the concept of informatics. A good question for discussion for the first week is to have the students look up definitions of informatics and then discuss in a thread....”

"At first I was a bit skeptical of how the challenge weeks would work. Having completed a couple of them now, I have to admit, that I really like them. It forces me to look at the week's readings in a whole different light. I think I look at them more critically. It makes me more of an active reader, than a passive reader. Thanks for the challenge!"

\section{B. Feedback}

Prompt and consistent feedback is essential in an online teaching environment, whether it consists of threaded discussion responses, email comments on papers and assignments, formal comments on student and group papers and projects, or real time conferencing. Feedback can be both individual and general to the group. In this respect, feedback is a critical teaching tool, especially when teaching medical professionals who are accustomed to giving and receiving feedback in their work. Both instructors provided consistent, prompt feedback in a timely fashion on students' discussion board messages and other assignments. The following are the comments from students on feedback:

“..........I often look forward to the instructors' comments to help solidify the discussion and round out the answer to the discussion questions"

“...I do find that the instructors' comments at the end of discussions are extremely helpful in bringing the entire discussion together...”

"Consistent feedback comments on the discussion board and emails"

"In terms of feedback for the course, I liked how the instructors saved comments for later in the class discussion in the last weeks. For me this helps the students develop a dialogue. In one previous class, the 
instructor was often first to post comments often terse in nature. I felt this inhibited my natural reaction to posting comments...."

In an online learning environment, it is important to provide answers students' questions in an efficient and timely manner. This strategy helps maintain students' motivation and keeps them engaged in the learning process. Both instructors made every effort to answers students' questions in maximum 24 hours time frame. One of the benefits of co-teaching was sharing this responsibility so that students could receive much quicker responses from us. Responses also enhanced the quality of our teaching as well as our collaboration. In the course evaluation, many of the students indicated that they appreciated the prompt responses to their postings.

\section{Final Project}

Students were required to do a final project with the option of an individual project or a group project. For those who preferred to do a group project, the project scope was assessed based on the number of students involved so that each participant had a portion for which s/he was responsible. The project proposal guideline was provided both for individual and group projects. A few students liked the group project idea and said:

“Term project in pairs was an excellent format!”

There were no negative comments about the instructors. Even though both instructors speak English as a second language, none of the students reported language or communication as negatively affecting their learning experience.

\section{LESSONS LEARNED}

This experience in international co-teaching provided us with a model for future collaborations as our program evolves and matures. The most challenging aspect of the experience was the additional time and effort needed to plan the course due to the need to exchange materials and ideas back and forth electronically (and asynchronously). This slowed the usual give and take process typical of a collaboration, especially in the early stages of development. At the same time, several benefits, some expected, some not, emerged from the collaboration:

1. The collaboration encouraged mutual learning from each other allowing a bilateral train-the-trainer concept. The first instructor increased her content knowledge of medical informatics and her efficiency as a medical educator. The second instructor learned how to transmit his extensive content knowledge to the online environment using sound principles of distance teaching pedagogy. This included the increased time requirement of online instruction due largely to the asynchronous nature of the teacher-student interface.

2. Sharing the responsibility of student feedback between the two instructors was beneficial to the instructors and students by the added timeliness and efficiency. This also encouraged effective coteaching compatibility, which is a significant component of successful co-teaching relationship. The second instructor was able to appreciate that prompt and timely feedback increased the student engagement in the learning process while it helped them build a strong learning community.

3. A model of online co-teaching emerged by experimenting with communication technologies. The advantages of technology-powered education made it possible to convert the traditional models of 
teamwork into creative teaching strategies on a global scale. This provided the second instructor with valuable professional development and the opportunity to increase his confidence as an educator.

4. Teaching online is a labor-intensive process for the instructor due to course preparation time, time spent teaching, asynchronous interaction with students, and office hours. The division of labor between two instructors encouraged uninterrupted instruction and eliminated potential bottlenecks in the discussion board postings.

\section{DISCUSSION AND CONCLUSION}

Modern medicine employs information technology to bridge the gap between what is known and what the doctor needs to know at the point of delivery of care. This course in medical informatics is an important option for future medical educators, and we are pleased to offer these coordinated and integrated educational opportunities. The web environment offers significant benefits in collaboration and enables co-teaching in an online, Web-based environment with advantages over the traditional classroom setting. The web format also offers an environment that is as effective as face-to-face teaching for "teach the teacher" activities that can be mutually beneficial to both co-teachers. Chrislip [20] states that collaboration is stronger than cooperation and partnership because it requires the consideration of shared power and may be defined as a "shared responsibility for achieving results" (p. 304).

In this distance learning course on medical informatics, both instructors found collaboration rewarding and were pleased with the outcome of this venture. First, this course resulted in a high-quality, first experience in teaching medical informatics online. Second, pedagogical transformation for the second instructor was smooth. Third, the first instructor was able to increase her content knowledge in the topic. The second instructor has now joined the core instructors group in this online masters program and will be teaching this course every year. In fact, the course was offered again in the Summer Quarter of 2006 with some minor modifications, and the second instructor taught it by himself. Course evaluation scores were very similar to the previous year. One of the student comments was very interesting:

Murat was very responsive to email questions. It was very interesting having an instructor outside of the US. I was a little overwhelmed at first with thinking of informatics globally but then I realized that we could put our own perspective into the assignments. I think this is a great course and Murat has much knowledge to share with all the students.

Although co-teaching requires thoughtful planning and additional time and effort to initiate, we believe that co-teaching online has tremendous potential and is a viable option for online educators who are separated by distance and, perhaps, time. Furthermore, pairing an experienced distance learning instructor with a distance learning novice can be a cost effective model for training new instructors in online teaching. It offers an opportunity for professional development for both the experienced and new online teachers, promotes diversity, and fosters professional collaboration. Online co-teaching also encourages instructional change and improves the quality of designing and teaching courses. Further research should be conducted to identify specific benefits and challenges of co-teaching and to evaluate the effectiveness of it in the training of new online instructors.

\section{REFERENCES}

1. Jonassen, D. H. Thinking technology. Educational Technology 34(4): 34-37, 1994. 
2. Austin, A. E. \& R. G. Baldwin. Faculty collaboration: enhancing the quality of scholarship and teaching. ASHE-ERIC Higher Education Report No. 7.Washington, DC: The George Washington University, 1991.

3. Montiel-Overall, P. Toward a theory of collaboration for teachers and librarians. School Library Media Research, 8: 2005.

4. Lewis, K. O. \& R. C. Baker. Development and Implementation of an Online Masters Degree in Education for Healthcare Professionals Program. Academic Medicine 80(2): 141-6, 2005.

5. Hersh, W. R. Medical informatics: Improving health care through information. JAMA 288(16): 1955-1958, Oct 232002.

6. Friend, M., M. Reising \& L. Cook. Co-teaching: An overview of the past, a glimpse at the present, and considerations for the future. Preventing School Failure 37(4): 6-10, 1993.

7. Cook, L. \& M. Friend. Co-teaching: Guidelines for creating effective practices. Teaching Exceptional Children 28: 1-16, 1995.

8. Spencer, S. An interview with Lynn Cook and June Downing: The Practicalities of Collaboration in Special Education Service Delivery. Intervention in School and Clinic 40(5): 296-300, 2005.

9. Young, S. S.-C. In search of online pedagogical models through investigating a changing teaching paradigm in the School for all community. Journal of Computer Assisted Learning 20(2): 133-150, 2004.

10. Lin, C.-B., S. S.-C.Young, T.-W. Chan \& Y.-H. Chen. Teacher-oriented adaptive Web-based environment for supporting practical teaching models: a case study of "school for all" Computers \& Education 44(2): 155-172, 2005.

11. Murawski, W. W. \& L. A. Dieker. Tips and strategies for co-teaching at the secondary level. Teaching Exceptional Children 36(5): 52-58, 2004.

12. Orlander, J. D., M. Gupta, B. G. Fincke, M. E. Manning \& W. Hershman. Co-teaching: A Faculty Development Strategy. Medical Education 34(4): 257-265, 2000.

13. Crow, J. \& L. Smith. Using co-teaching as a means of facilitating interprofessional collaboration in health and social care. $J$ Interprof Care 17(1): 45-55, 2003.

14. Adams, L. \& K. Cessna. Designing systems to facilitate collaboration: Collective wisdom from Colorado. Preventing School Failure 35(4): 37-42, 1991.

15. Bradley, D. F., M. E. King-Sears \& D. M. Tessier-Switlick. Teaching students in inclusive settings: From theory to practice. Boston: Allyn \& Bacon, 1997.

16. Murawski, W. W. \& H. L. Swanson. A meta-analysis of coteaching research: Where are the data? Remedial and Special Education 22(5): 258-267, 2001.

17. Keefe, E. B., V. Moore \& F. Duff. The four "knows" of collaborative teaching. Teaching Exceptional Children 36(5): 36-41, 2004.

18. Stevenson, C. B., R. L. Duran, R. A. Barrett \& G. C. Calarulli. Fostering faculty collaboration in learning communities. Innovative Higher Education 30(1): 23-37, 2005.

19. Dieker, L. The Co-teaching Lesson Plan Book. Whitefish Bay, WI: Knowledge by Design, Inc., 2002.

20. Chrislip, D. Collaborative Leadership Fieldbook: A Guide for Citizens and Civic Leaders. San Francisco, CA: Jossey-Bass, 2002.

\section{ABOUT THE AUTHORS}

Kadriye O. Lewis, Ed.D is Field Service Assistant Professor of Pediatrics at Cincinnati Children's Hospital Medical Center. She coordinates and supervises the educational activities within Division of General Pediatrics of the Cincinnati Children's Hospital Medical Center, including program development, curriculum and evaluation. She is the education consultant to the medical center's faculty development program, an integrated, multi-level, multidisciplinary program of faculty development in teaching. Most recently, in collaboration with the College of Education at the University of Cincinnati, she and her colleague, Dr. Raymond C. Baker have developed an online Master's Degree in Education for Physicians 
and Other Healthcare Professionals, which has been offered both nationally and internationally since 2002 (www.cincinnatichildrens.org/masters). She is the associate director of the program and also teaches two courses online.

Murat Sincan, MD is currently working in the Department of Medical Education and Informatics at Hacettepe University Faculty of Medicine as an academic expert. He received his Doctor of Medicine degree from Hacettepe University Faculty of Medicine in 1999. He is currently pursuing his PhD in Information Sciences at the Informatics Institute of Middle East Technical University. Dr. Sincan was a Research Fellow at the Children's Hospital Boston in 2004 under the Fogarty International Program of NIH. He teaches undergraduate and graduate level courses at Hacettepe University Faculty of Medicine and Institute of Health Sciences. Dr. Sincan is an active member of American Medical Informatics Association and a former General Secretary of the Turkish Medical Informatics Association. He is currently involved in "The HacetTELE Telemedicine Project” funded by Devlet Planlama Teskilati (the State Planning Organization). He also received funding from "International Mental Health and Developmental Disabilities (MHDD) Research Training Program" Fogarty/NIH and "SBIR Phase I Medical Research Training Program Web Collaboratory” NIMH/NIH. 